\title{
Prevalence of Cattle Piroplasmosis and Some Associated Risk Factors in Lower Shabelle Region, Somalia
}

\section{Aamir Muse Osman ${ }^{1 *}$, Kalthoum Moallim Yususf ${ }^{1}$ and Abdalla Mohamed Ibrahim $^{2}$}

${ }^{1}$ Department of Parasitology, Collage of Veterinary Medicine, Abrar University Mogadishu, Somalia

${ }^{2}$ Abrar Research and Training Centre, Abrar University Mogadishu, Somalia

*Corresponding author: Aamir Muse Osman, Department of Parasitology, Collage of Veterinary Medicine, Abrar University Mogadishu, Somalia Email: aamirmuse@gmail.com

\section{Research Article}

Volume 5 Issue 2

Received Date: July 29, 2020

Published Date: October 02, 2020

DOI: $10.23880 /$ oajvsr-16000200

\section{Abstract}

Background: Tick-borne diseases (TBDs) cause significant losses among livestock and impact the livelihoods of livestock communities worldwide including Somalia. Infections with Babesia and Theileria species are endemic in Somalia yet there is a lack of adequate information on their prevalence.

Objective: The present study aimed to assess the prevalence of Cattle Piroplasmosis in three districts of Lower Shabelle Region, Somalia using microscope and to identify the available tick species found in the sampled cattle during the study.

Methods: A total of 127 Cattle blood were examined for Piroplasms (Babesia and Theileria) using Microscope during January to February 2020. The available ticks were collected in 70\% Ethanol.

Results: The overall prevalence of Piroplasmosis was 123/127 (96.9\% 95\% CI: 92.1-99.1\%). About 45 out of 127 (35.4\% 95\% CI: 27.1-44.1\%) samples were positive for either Theileria or Babesia, while 78 out 127 (61.4\% 95\% CI: 52.4-69.9\%) samples were mixed infected with both them. Risk factors like age, body condition, sex, lymphnode enlargement and presence of ticks were found to be insignificantly associated with Babesiosis and Theileriosis. For both infections the mean PCV of infected animals was insignificantly lower than non-infected animals. Six tick species belonging to two genera (Rhipicephalus and Amblyomma) were identified in the investigated cattle, including, $R$. pulchellus (64.7\%), $R$. (Boophilus) microplus, (2\%) $R$. (Boophilus) decoloratus (2\%), R.evertsi, (3.9\%) A. gemma (15.7\%) and A. lepidum (11.8\%).

Conclusion: This study revealed a very high prevalence of Piroplasmosis in the study area and co-infections were more common than single infections. Further studies in other areas in the country are recommended.

Keywords: Babesiosis; Cattle; Somalia; Theileriosis; Tick

\section{Introduction}

Babesiosis and Theileriosis are important tick-borne diseases of Cattle worldwide including Somalia. They are caused by the protozoan parasites, Babesia and Theileria spp respectively [1]. In Somalia, Cattle Piroplasmosis is great concern since the country possesses population of Cattle that estimated at nearly 5,100,000 heads in 2013. The herd structure is comprised of $80-87 \%$ female herd with $20-30 \%$ lactating. It is estimated that the average milk production per cow is 2 litres per day with an estimated gate farm price of 1 USD [2]. 


\section{Open Access Journal of Veterinary Science \& Research}

Cattle Babesiosis is caused by Babesia bovis and $B$. bigemina and the disease is transmitted by Rhipicephalus ticks [3]. Animals suffering from acute Babesiosis can have a variety of symptoms such as fever, increased heart rate, increased respiratory rate, abnormal mucous membrane color, and low PCV values. Although these symptoms are very typical, they are not pathognomonic, and animals with chronic infections can be asymptomatic carriers $[4,5]$.

Cattle theileriosis is mostly cause Theileria annulata and Theileria parva [6]. They are transmitted by ixodid ticks [7]. It is characterized by high fever, weakness, weight loss, conjunctival petechia, enlarged lymph nodes and anaemia [8].

B. bovis, B. bigemina, T. parva, and T. annulata cause mortalities and morbidities leading to losses in production of milk, meat, and other livestock by-products. Consequently, they cause severe economic losses to livestock farmers involved in dairy and beef production in tropical and subtropical regions [9]. The diagnosis of these diseases in Somalia Cattle have depend on mostly on microscopic examination of blood smears [10] and antibody detection $[11,12]$. However, these studies have been limited to a few tick-borne diseases with all of the studies were lack adequate information to assess the correlation of different tick species with disease occurrence despite its significant role in disease transmission and also which is critical for the control and prevention of these diseases. Hence, there is scarcity of information on Cattle Piroplasmosis at national level and in Lower shabelle region in particular. Therefore, the present study aimed to assess the prevalence of Cattle Piroplasmosis in three districts of Somalia using microscopic detection and to identify different tick species associated with occurrence of Piroplasmosis.

\section{Materials and Methods}

\section{Study Area}

Lower Shabelle region is one of the eighteen regions of the Federal Republic of Somalia. It comprises eight districts, three of them were included this study namely Afgoi (Latitude: $2^{\circ} 08^{\prime} 17.16^{\prime \prime} \mathrm{N}$ and Longitude: $45^{\circ} 07^{\prime} 16.32^{\prime \prime} \mathrm{E}$ ), Awdhegle (Latitude: $1.9805^{\circ} \mathrm{N}$, Longitude: $44.8330^{\circ} \mathrm{E}$ ) and Wanleweyn (Latitude: $2^{\circ} 37>6.60 » \mathrm{~N}$ and Longitude: $44^{\circ} 53$ > 37.68» E).

\section{Study Population and Samples}

Blood Collection: A total of 127 Cattle (119 females and 8 males), <2 years-old ( $\mathrm{n}=10), 2-5$ years-old $(\mathrm{n}=50)$, and $>5$ years-old $(n=67)$ from Awdhegle $(n=65)$, Wanlaweyn $(n=44)$ and Afgoye $(n=18)$ districts were sampled. Blood samples were collected by jugular venipuncture. Three milliliters were placed into EDTA tubes for packed cell volume (PCV) measurement and microscopical detection of Piroplasms. Animals with PCV less than $24 \%$ were considered to be anaemic [13].

\section{Tick Collection}

All visible ticks were manually collected by using forceps in a bottles containing $70 \%$ ethanol from each cattle. The ticks were then transported to the Abrar Research and Training Centre (ARTC) in Abrar University, MogadishuSomalia for identification.

\section{Laboratory Examination}

Thin dried Giemsa stained blood smears were prepared and investigated under microscope for Babesia and Theileria piroplasms.

Packed cell volume determination: Blood was collected on capillary tubes and centrifuged at 12,000 rpm for 5 minutes to evaluate the level of anaemia in the examined animals.

Tick identification: Ticks were identified to stages and species level using a stereomicroscope according to their morphological key.

\section{Data Analysis}

The PCV data were not normally distributed (ShapiroWilk normality test, $W=0.98, P=0.021$ ). Therefore, a nonparametric Mann-Whitney test was used to compare the PCV concentration between Babesia and Theileria-infected and non-infected Cattle. The data obtained from the field were recorded in notebook and later stored in Microsoft Excel 2013 and analysed using software SPSS $₫$ version 25. Descriptive statistics were presented as tables. The association of Cattle Babesiosis and Theileriosis with different independent variables (age, sex, body condition, lymphnode enlargement and presence of ticks) was analysed using logistic regression.

\section{Results}

\section{Microscopic Identification of Cattle Piroplasmosis}

A total of 127 Cattle blood were examined for Babesiosis and Theileriosis and overall prevalence was 123/127 (96.9\% 95\% CI: 92.1-99.1\%). 45 out of 127 (35.4\% 95\% CI: 27.1$44.1 \%$ ) samples were positive for at least one Piroplasmas, while 78 out 127 (61.4\% 95\% CI: 52.4-69.9\%) samples were mixed infection both Theileria and Babesia.

The highest prevalence of Cattle Babesiosis recorded (86.2\%) was Awdhegle flowed (36.2\%) was walaweyn and 


\section{Open Access Journal of Veterinary Science \& Research}

the lowest was (15.5\%) in Afgoye. However, there were no statistical significant difference between different localities and positivity for Cattle Babesiosis $(\chi 2=4.86, \mathrm{P}=0.088)$. The highest prevalence of Cattle Theileriosis recorded (61.9\%) was Awdhegle, flowed (61.4\%) was walaweyn and the lowest was $(6.0 \%)$ in Afgoye. However, there were statistical significant difference between different localities and positivity for Cattle Theileriosis $\left(\chi^{2}=17.85, \mathrm{P}=0.00\right)$.
The prevalence of Cattle Babesiosis based on sex of the study animals was found to be insignificantly higher in female 109/119 (91.6\% 95\% CI: 85.1-95.9\%) than male 7/8 (87.5\% 95\% CI: 47.4-99.7\%), Prevalence of Theileriosis was 77/119 (64.7\%, 95\% CI: 55.4-73.2\%) in Female and 7/8 (87.5\%, 95\% CI: 47.4-99.7\%) found in male and to be insignificantly $(\mathrm{p}=0.356)$.

\begin{tabular}{|c|c|c|c|c|c|c|c|c|c|c|c|}
\hline \multirow{2}{*}{\multicolumn{2}{|c|}{ Variables }} & \multicolumn{5}{|c|}{ Babesiosis } & \multicolumn{5}{|c|}{ Theileriosis } \\
\hline & & \multirow{2}{*}{$\begin{array}{c}+/ \mathbf{n} \\
17 / 18\end{array}$} & \multirow{2}{*}{\begin{tabular}{|c|}
$\begin{array}{c}\text { Prevalence } \\
\text { \% (95\% } \\
\text { CI:) }\end{array}$ \\
$94.4(72.7-$ \\
$99.8 \%)$ \\
\end{tabular}} & \multirow{2}{*}{\begin{tabular}{|l|} 
P-value \\
0.6203 \\
\end{tabular}} & \multirow{2}{*}{\begin{tabular}{|c|}
$\chi^{2}$ \\
0.914
\end{tabular}} & \multirow{2}{*}{\begin{tabular}{|c|} 
OR \\
$\mathbf{( 9 5 \%}$ \\
$\mathbf{C I})$ \\
$2.7(0.3-$ \\
$23.1)$ \\
\end{tabular}} & \multirow{2}{*}{$\begin{array}{l}+/ \mathbf{n} \\
5 / 18\end{array}$} & \multirow{2}{*}{\begin{tabular}{|c|}
$\begin{array}{c}\text { Prevalence \% } \\
\text { (95\% CI:) }\end{array}$ \\
$27.8(9.7-53.5)$
\end{tabular}} & \multirow{2}{*}{$\begin{array}{r}\text { P-value } \\
0.000\end{array}$} & \multirow{2}{*}{$\begin{array}{c}\chi^{2} \\
17.87\end{array}$} & \multirow{2}{*}{\begin{tabular}{|c} 
OR (95\% \\
CI)
\end{tabular}} \\
\hline \multirow{3}{*}{ District } & Afgoye & & & & & & & & & & \\
\hline & Wanlaweyn & $42 / 44$ & $\begin{array}{c}95.4(84.5- \\
99.4 \%)\end{array}$ & 0.203 & 2.502 & \begin{tabular}{|c|}
$3.4(0.7-$ \\
$16.4)$
\end{tabular} & $27 / 44$ & $\begin{array}{c}\text { 61.4(45.5- } \\
75.6)\end{array}$ & 0.0561 & 4.568 & $0.4(0.2-0.9)$ \\
\hline & Awdhegle & $56 / 65$ & $\begin{array}{c}\text { 86.1(75.4- } \\
93.4 \%)\end{array}$ & ref & & & $52 / 65$ & $\begin{array}{c}80.0(68.2- \\
88.9)\end{array}$ & ref & & \\
\hline \multirow{2}{*}{ Sex } & Female & $109 / 119$ & $\begin{array}{c}91.6(85.1- \\
95.9)\end{array}$ & 0.9999 & 0.159 & $\begin{array}{c}1.6(0.2- \\
13.9)\end{array}$ & $77 / 119$ & $\begin{array}{c}64.7(55.4- \\
73.2)\end{array}$ & 0.356 & 1.739 & $0.3(0.0-2.2)$ \\
\hline & Male & $7 / 8$ & $\begin{array}{c}87.5(47.4- \\
99.7)\end{array}$ & ref & & & $7 / 8$ & $\begin{array}{c}87.5(47.4- \\
99.7)\end{array}$ & ref & & \\
\hline \multirow{3}{*}{ Age } & $<2$ years & $8 / 10$ & $\begin{array}{c}80(44.4- \\
97.5)\end{array}$ & 0.553 & 1.14 & $\begin{array}{c}0.4(0.1- \\
2.3)\end{array}$ & $7 / 10$ & $70(34.8-93.3)$ & 0.662 & 0.632 & $1.8(0.4-7.5)$ \\
\hline & $2-5$ years & $46 / 50$ & $\begin{array}{c}92(80.8- \\
97.8) \\
\end{array}$ & 0.999 & 0.03 & $\begin{array}{c}1.1(0.3- \\
4.2)\end{array}$ & $39 / 50$ & 78 (64.0-88.5) & 0.026 & 5.765 & $2.7(1.2-6.2)$ \\
\hline & $>5$ years & $61 / 67$ & $\begin{array}{c}91(81.5- \\
96.6)\end{array}$ & ref & & & $38 / 67$ & $\begin{array}{c}56.7(44.0- \\
67.9)\end{array}$ & ref & & \\
\hline \multirow{2}{*}{$\begin{array}{c}\text { Tick } \\
\text { presence }\end{array}$} & No & $87 / 98$ & $\begin{array}{c}88.8(80.8- \\
94.3)\end{array}$ & 0.377 & 1.582 & $\begin{array}{c}0.3(0.0- \\
2.3)\end{array}$ & $65 / 98$ & $\begin{array}{c}66.5(56.1- \\
75.6)\end{array}$ & 0.999 & 0.0065 & $1.0(0.4-2.5)$ \\
\hline & Yes & $28 / 29$ & $\begin{array}{c}96.6(82.2- \\
99.9)\end{array}$ & ref & & & $19 / 29$ & $\begin{array}{c}65.5(45.7- \\
82.1) \\
\end{array}$ & & & \\
\hline \multirow{2}{*}{ Lymphnode } & Normal & $113 / 124$ & $\begin{array}{c}91 \text { (81.2- } \\
96.7)\end{array}$ & 0.5188 & 2.049 & $\begin{array}{c}5.1(0.4- \\
61.3)\end{array}$ & $84 / 124$ & $\begin{array}{c}67.7(58.8- \\
75.9)\end{array}$ & 0.999 & 0.0015 & $\begin{array}{c}1.1(0.1- \\
11.9)\end{array}$ \\
\hline & Enlargement & $2 / 3$ & $\begin{array}{c}66.7(9.4- \\
99.2)\end{array}$ & ref & & & $2 / 3$ & $66.7(9.4-99.2)$ & ref & & \\
\hline \multirow{3}{*}{$\begin{array}{c}\text { Body } \\
\text { condition }\end{array}$} & Good & $60 / 66$ & $\begin{array}{c}90.9(86.7- \\
99.1)\end{array}$ & 0.344 & 1.778 & $\begin{array}{c}2.5(0.6- \\
9.9)\end{array}$ & $40 / 66$ & $\begin{array}{c}60.6(47.8- \\
72.4)\end{array}$ & 0.365 & 1.379 & $0.5(0.2-1.6)$ \\
\hline & Moderate & $36 / 41$ & $\begin{array}{c}87.8(73.8- \\
95.9)\end{array}$ & 0.655 & 0.651 & $\begin{array}{c}1.8(0.4- \\
7.6)\end{array}$ & $29 / 41$ & $\begin{array}{c}70.1(54.5- \\
83.9)\end{array}$ & 0.9771 & 0.1218 & $0.8(0.2-2.7)$ \\
\hline & Poor & $16 / 20$ & $\begin{array}{c}80(56.3- \\
94.2)\end{array}$ & ref & & & $15 / 20$ & 75 (50.9-91.3) & ref & & \\
\hline
\end{tabular}

Abbreviations: +, number of positive animals; $\mathrm{n}$, number of samples; 95\% CI, 95\% confidence interval; OR, odds ratio

Table 1: Prevalence of Cattle Piroplasmosis within each variable studied.

The highest prevalence of Cattle Babesiosis was recorded in 2-5 years old 46/50 (92\%, 95\% CI: 80.8-97.8\%), 


\section{Open Access Journal of Veterinary Science \& Research}

flowed by $>5$ years old $61 / 67$ (91.0\%, 95\% CI: 81.5-96.6\%) and $<2$ years was $8 / 10(80.0 \%, 95 \% \mathrm{CI}: 44.4-97.5 \%)$. This difference was observed to be statistically insignificant $(\mathrm{P}=0.761)$, the highest prevalence of Cattle Theileriosis was $2-5$ years old $39 / 50$ (78.0\%, 95\% CI: $64.0-88.5 \%)$, followed $<2$ years old $7 / 10(70.0 \%, 95 \%$ CI: $34.8-93.3 \%)$ and the lowest was >5 years old 38/67 (56.7\%, 95\% CI: 44.0-67.9\%). This difference was observed to be statistically insignificant $(\mathrm{P}=0.053)$ (Table 1).

\section{PCV Determination}

The mean PCV concentration for Cattle was 0.26 l/l. No statistical difference $(U=510.5, Z=-1.05, P=0.294)$ was found in mean PCV between Babesia- positive $(0.27 \mathrm{l} / \mathrm{l})$ and Babesia-negative Cattle $(0.28 \mathrm{l} / \mathrm{l})$. Similarly, No statistical difference $(U=1507.5, Z=-1.42, P=0.155)$ was found in mean PCV between Theileria- positive $(0.27 \mathrm{l} / \mathrm{l})$ and Theielria-negative Cattle (0.29 l/l).

\section{Tick Identified in the Study Area}

The overall tick infestation of Cattle was 34/127 (26.8\%), The identified tick species in study area was six species. The overall, six tick species belonging to the Rhipicephalus and Amblyomma genera, $R$. pulchellus (64.7\%), R. (Boophilus) microplus, (2\%) R. (Boophilus) decoloratus (2\%), R.evertsi, (3.9\%) A.gemma (15.7\%), and A.lepidum (11.8\%)(Table 2).

\begin{tabular}{|c|c|c|c|c|c|c|}
\hline \multirow{2}{*}{ Tick identified } & \multicolumn{3}{|c|}{ Babesiosis } & \multicolumn{3}{c|}{ Theileriosis } \\
\cline { 2 - 7 } & $\mathbf{+} / \mathbf{n}$ & $\mathbf{\%}$ & $\mathbf{9 5 \% C I :}$ & $\mathbf{+ / n}$ & $\mathbf{\%}$ & $\mathbf{9 5 \% C I :}$ \\
\hline R.pulchellus & $15 / 28$ & 53.6 & $33.9-72.5$ & $11 / 19$ & 57.9 & $33.5-79.8$ \\
\hline $\begin{array}{c}\text { Mixed R. pulchellus with } \\
\text { others }\end{array}$ & $7 / 28$ & 25.0 & $10.7-44.9$ & $4 / 19$ & 21.1 & $6.1-45.6$ \\
\hline A.lepidium & $3 / 28$ & 10.7 & $2.3-28.2$ & $2 / 19$ & 10.5 & $1.3-33.1$ \\
\hline A.gemma & $2 / 28$ & 7.1 & $0.9-23.5$ & $1 / 19$ & 5.3 & $0.1-26.0$ \\
\hline mixed with other species & $1 / 28$ & 3.6 & $0.1-18.4$ & $1 / 19$ & 5.3 & $0.1-26.0$ \\
\hline P-value & \multicolumn{7}{|c|}{0.166} & & 0.775 & \\
\hline
\end{tabular}

Table 2: Prevalnce of Cattle Babesiosis and Theileriosis associated with identified tick species

Mixed R. pulchellus with others: R. pulchellus+Rhipicephalus spp.

Mixed with other species: mixed of Amblyomma spp.

\section{Discussion}

In the present study, the prevalence of Cattle Babesiosis and Theileriosis in Lower shabelle region of Somalia was $91.3 \%$ and $66.1 \%$ respectively. The prevalence of Babesiosis of this study is higher than the study reported by Caille [12]. Theileriosis prevalence was higher than that reported by Heuer, et al. [10] and Schoepf, et al. [11], and Lower then study reported by Caille [12]. The slight rise of prevalence might be resulted from continuous migration of Cattle search for better grazing. This was expected because, the large part of the grazing area available in southern part of the country or may be caused by different sampling times, sampling strategies and locations.

In the current study a slightly lower prevalence rate in male cattle was recorded (87.5\%), as compared to female cattle $(91.6 \%)$ of Babesiosis. However, the difference in the prevalence of positivity between the two sexes of the cattle as not statistically significant $(P>0.05)$. This is consistent with findings of previous studies that observed similar findings [14]. The reason, why in the current study it was observed that both sexes were found to be equally exposed to Babesia infection, is the fact that cattle usually graze together in the grassland and overnight in stalls. This practice is likely to facilitate the transfer of ticks within the herds and eventually, facilitated the equal distribution of ticks among cattle leading to equal exposure in both sexes [15]. While Theileriosis male Cattle (87.5\%) is higher prevalence then female Cattle (64.1\%) with statistically insignificant $(\mathrm{P}>0.05)$. This result is in agreement with the finding of the study in Uganda [16]. The reason, Male cattle were associated with a slightly higher probability of infection with Theleria than females and castrates, that may be due to a reduction in activity in the individual associated with castration and a reduction of testosterone levels in castrates [17]. They were also reported that, Lower physiological activity in females and castrates is associated with lower grazing activity resulting in a reduced probability of the animal encountering to the tick and therefore exposure to infection with Theileria.

Increasing age has been frequently reported to be associated with increased TBDs prevalence [18]. The result of this study also showed as there was a clear gradient of age effects where the risk of exposure increased with age in 


\section{Open Access Journal of Veterinary Science \& Research}

both infections (Theileriosis and Babesiosis). Insignificantly $(\mathrm{P}=0.761)$ highest prevalence of Cattle Babesiosis was recorded in 2-5 years flowed $>5$ years and lowest $<2$ year old. This result in line with the finding of studies conducted Amorim, et al. [19]. While Theileriosis, the highest prevalence was recorded 2-5 years flowed $<2$ years and lowest $>5$ years old. This agreed by Kundave, et al. [20].

Furthermore, the high prevalence in adult animals could be due to the following reasons: Calves under the age of two years remained in paddocks close to homesteads while adults grazed away far in the field. In communal grazing areas, animal met with others from different places in which some could be infested with ticks, thus facilitating the spread of ticks from one herd to another [21]. It is a well-known fact that handling of calves for nursing is easier to farmers than handling adult animals. Therefore, it is possible that farmers in this study were able to de-tick calves rather than the adult cattle.

The PCV of individual animals is a useful indicator of anaemia which is recognized as the most important consequence of several ticks born disease including Babesiosis and Theileriosis in cattle [4]. In the present study, No statistical difference $(U=510.5, Z=-1.05, P=$ $0.294)$ was found in mean PCV between Babesia- positive $(0.27 \mathrm{l} / \mathrm{l})$ and Babesia-negative Cattle $(0.28 \mathrm{l} / \mathrm{l})$. Similarly, No statistical difference $(U=1507.5, Z=-1.42, P=0.155)$ was found in mean PCV between Theileria- positive $(0.27$ l/l) and Theielria-negative Cattle (0.29 l/l). The difference in mean PCV of the two groups could be attributed to the severe haemolytic process associated the presence of piroplams inside the erythrocytes and destruction of large numbers of these erythrocytes by the parasite thereby resulting in hemoglobinaemia and consequently hemoglobinuria [20].

Various tick species such as Rhipicephalus Spp. etc. are the most likely known source for Babesia and Theileria infections in the tropics [3]. During collection of blood samples, the existence of ticks on the environment and infestation on cattle was observed; this is similar to the findings of Pegram [23].

In conclusion, this study revealed a very high prevalence of Piroplasmosis close to $100 \%$ in the study area and coinfections were more common than single infections. This might have implications for potential interactions of pathogens and the patterns of clinical symptoms. Further studies and investigation of the disease in other areas in the country should be encouraged.

\section{Acknowledgements}

The authors thank Abrar University for their support to carry out this work.

\section{Conflict of Interest}

The authors declare that they have no conflict of interest regarding the publication of this article.

\section{References}

1. Jirapattharasate C, Franck P, Moumouni A, Cao S, Iguchi A, et al. (2015) Molecular epidemiology of bovine Babesia spp and Theileria orientalis parasites in beef cattle from northern and northeastern Thailand. Parasitology International 65(1): 62-69.

2. ICPALD (2015) The contribution of livestock to the Somali economy, IGAD Centre for Pastoral Areas and Livestock Development, pp: 8.

3. OIE (2013) Bovine Babesiosis Technical Disease Card.

4. Kocan KM, de la Fuente J, Blouin EF, Coetzee JF, Ewing SA (2010) The natural history of Anaplasma marginale. Veterinary parasitology 167(2-4): 95-107.

5. El-Ashker M, Hotzel H, Gwida M, El-Beskawy M, Silaghi C, et al. (2015) Molecular biological identification of Babesia, Theileria, and Anaplasma species in cattle in Egypt using PCR assays, gene sequence analysis and a novel DNA microarray. Veterinary parasitology 207(34): 329-334.

6. Kohli S, Atheya UK, Thapliyal A (2014) Prevalence of theileriosis in cross-bred cattle: its detection through blood smear examination and polymerase chain reaction in Dehradun district, Uttarakhand, India Veter World 7(3): 168-171.

7. Santos M, Soares R, Costa P, Amaro A, Inacio J, et al. (2013) Revisiting the Tams1-encoding gene as a speciesspecific target for the molecular detection of Theileria annulata in bovine blood samples. Ticks Tick-borne Dis 4: $72-77$.

8. Radostits OM, Gay CC, Hinchcliff, KW, Constable PD (2007) Veterinary medicine: A textbook of the diseases of cattle, horses, sheep, pigs and goats, $10^{\text {th }}$ (Edn.), Elsevier, Philadelphia, pp: 1522-1532.

9. Jongejan F, Uilenberg G (2004) The global importance of ticks. Parasitology 129: S3-S14.

10. Heuer CH, Nauheiner MP, Baumann O Zessin K, Jama H, A Nuux H, et al. (1990a) Disease survey data of cattle herds in Central Somalia. GTZ/CRDP project report No.13.

11. Schoepf K, Mohamed HAM, Katende JM (1984) 


\section{Open Access Journal of Veterinary Science \& Research}

Observation on blood borne parasites of domestic livestock in the lower Juba region of Somalia. Trop Anim Hlth Prod 16(4): 227-232.

12. Caille JY (1987) Serologische untersuchungen uber verbreitung und saisonales vorkommen von bluprotozoen bei verschiedenen nutztieren in Somalia. Free university Berlin, Berlin, Thesis.

13. OIE (2008) Manual of diagnostic tests and vaccines for terrestrial animals. Paris.

14. Tembue AA, Silva FJ, Silva JB, Santos TM, Santos HA, et al. (2011) Risk factors associated with the frequency of antibodies against Babesia bovis and Babesia bigemina in cattle in southern Mozambique. Pesquisa Veterinária Brasileira 31(8): 663-666.

15. Abdullah MD, Shariful SM, Alamgir Hossain (2015) Prevalence of theileriosis and babesiosis in cattle in Sirajganj district of Bangladesh. Open Access Research Article 2(1): 79-86.

16. Muhanguzi D, Picozzi K, Hatendorf J, Thrusfield M, Welburn SC, et al. (2014) Prevalence and spatial distribution of Theileria parva in cattle under croplivestock farming systems in Tororo District, Eastern Uganda. Parasites \& vectors 7: 91.

17. Marti S, Realini CE, Bach A, Pérez-Juan M, Devant M (2013) Effect of castration and slaughter age on performance, carcass, and meat quality traits of Holstein calves fed a high-concentrate diet. Journal of animal science 91(3): 1129-1140.

18. Atif FA, Khan MS, Muhammad F, Ahmad B (2013) Seroepidemiological study of Anaplasma marginale among cattle. J Anim Plant Sci 23(3): 740-744.

19. Amorim LS, Wenceslau AA, Carvalho FS, Carneiro PL, Albuquerque GR (2014) Bovine babesiosis and anaplasmosis complex: diagnosis and evaluation of the risk factors from Bahia, Brazil. Revista brasileira de parasitologia veterinaria=Brazilian journal of veterinary parasitology 23(3): 328-336.

20. Kundave VR, Patel AK, Patel PV, Hasnani JJ, Joshi CG (2015) Detection of theileriosis in cattle and buffaloes by polymerase chain reaction. J of Parasit Dis 39(3): 508513.

21. Estrada A, Salman M (2013) Current limitations in the control and spread of ticks that affect livestock. Agriculture 3(2): 221-235.

22. Dantas-Torres F, Alves LC, Uilenberg G (2017) Babesiosis. Arthropod Borne Diseases, $1^{\text {st }}$ (Edn.), Springer International Publishing, Switzerland, pp: 347-354.

23. Pegram RG (1976) Ticks (Acarina, Ixodoidea) of die northern regions of the Somali Democratic Republic. Bull Ent Res 2(1954): 345-363. 